\title{
Penambahan Gliserol terhadap Karakteristik Bioplastik dari Komposit Pati Aren dan Glukomanan
}

\author{
Sari Purnavita*, Dyionisius Yoga Subandriyo, Ayu Anggraeni \\ Program Studi Diploma Tiga Teknik Kimia Politeknik Katolik Mangunwiiaya \\ Jl. Sriwijaya No 104, Semarang Jawa Tengah 50242 Indonesia \\ Email: saripurnavita.2018@gmail.com
}

\begin{abstract}
Abstrak
Penelitian ini bertujuan untuk mengetahui pengaruh rasio glukomanan dan pati aren dengan penambahan gliserol terhadap karakteristik bioplastik yang dihasilkan. Pembuatan bioplastik dilakukan dengan mencampurkan larutan glukomanan dan larutan pati aren, selanjutnya dilakukan penambahan gliserol dan poli vinil alkohol. Campuran tersebut dipanaskan pada suhu $80^{\circ} \mathrm{C}$ selama 20 menit, hasil pencampuran kemudian dimasukkan cetakan dan dikeringkan dengan oven hingga menjadi lembaran, Selanjutnya bioplastik tersebut diuji karakteristiknya yang meliputi ketahanan air, tensile strength dan tensile elongation. Rasio glukomanan terhadap pati aren yaitu $1: 0,5 ; 1: 1 ; 1: 1,5$; dan $1: 2$ Serta jumlah penambahan gliserol yaitu : $0 \mathrm{ml}$ dan $10 \mathrm{ml}$. Hasil penelitian menunjukkan bahwa berbagai rasio glukomanan dan pati aren dengan penambahan gliserol berpengaruh terhadap karakteristik bioplastik. Pada penambahan gliserol $0 \mathrm{ml}$ (tanpa gliserol), komposit bioplastik dengan perbandingan glukomanan : pati aren sebesar 1:1 menghasilkan nilai ketahanan terhadap air yang tertinggi, nilai tensile strength yang cukup tinggi, dan morfologi yang baik, tetapi nilai tensile elongation rendah. Sedangkan pada percobaan dengan penambahan gliserol $10 \mathrm{ml}$, komposit bioplastik dengan perbandingan glukomanan : pati aren sebesar 1:1 menghasilkan nilai tensile elongatiom yang tertinggi, morfologi bagus tetapi nilai tensile strength dan ketahanan airnya rendah.
\end{abstract}

Kata kunci: bioplastik, glukomanan, pati aren, gliserol

\section{Abstract}

\section{Addition of Glycerol Bioplastic Characteristics of Palm and Glucomannan Composites}

Aim of this research to determine the effect of glucomannan ratio and sugar palm starch with the addition of glycerol to the bioplastic characteristics. Making of bioplastics by mixing glucomannan solution and sugar palm starch solution, then addition of glycerol and polyvinyl alcohol. The mixture is heated at $80^{\circ} \mathrm{C}$ for 20 minutes, the result of mixing afer that put into a mold and dried in the oven until it becomes a sheet. After that, the characteristics of the bioplastics were tested which included water resistance, tensile strength and tensile elongation. The ratio of glucomannan to sugar palm starch is 1:0.5; 1:1; 1:1,5; and 1:2 And the amount of glycerol addition are: $0 \mathrm{ml}$ and $10 \mathrm{ml}$. The results showed that the ratio of sugar palm starch and glucomannan with the addition of glycerol affected the bioplastic characteristics. At the addition of glycerol $0 \mathrm{ml}$, bioplastic composites with glucomane: palm starch ratio of 1:1 produce the highest water resistance value, high tensile strength value, and good morfology but low tensile elongation value. Whereas in experiments with the addition of $10 \mathrm{ml}$ of glycerol, bioplastic composites with a glucomane: palm starch ratio of 1:1 produced the highest tensile elongatiom value and good morfology result but the value of tensile strength and water resistance was low

Keywords: bioplastics, glucomannan, palm starch, glycerol 


\section{PENDAHULUAN}

Rata - rata orang Indonesia menghasilkan sampah $0,5 \mathrm{~kg}$ dan $13 \%$ diantaranya adalah plastik. Sampah plastik menduduki peringkat ketiga dengan jumlah 3.6 juta ton per tahun atau 9\% dari jumlah total produksi sampah. Dari seluruh sampah yang ada, 57\% ditemukan di pantai berupa sampah plastik. Sebanyak 46 ribu sampah plastik mengapung di setiap mil persegi samudera bahkan kedalaman sampah plastik di Samudera Pasifik sudah mencapai hampir 100 meter.

Berlimpahnya penggunaan plastik menimbulkan efek limbah yang begitu besar dan sulit terurai oleh mikroorganisme karena jenis plastik yang beredar di pasaran saat ini adalah plastik sintetik. Berbagai program dan kampanye seperti 3R yaitu mengurangi (reduce), menggunakan kembali (reuse), dan mendaur ulang (recycle) telah dilakukan sejak lama untuk menanggulangi permasalahan di atas namun tetap saja masalah plastik bagi lingkungan belum menemui solusi yang tepat untuk menanganinya.

Salah satu upaya untuk menanggulangi masalah tersebut adalah dengan mengganti plastik yang tidak mudah terurai dengan bioplastik. Bioplastik merupakan plastik yang dibuat dari bahan alami yang dapat diuraikan oleh mikroorganisme, sehingga lebih ramah lingkungan bila dibandingkan dengan plastik komersial.

Bahan yang sering digunakan dalam sintesis bioplastik adalah bahan alami polisakarida. Indonesia sendiri merupakan salah satu negara yang kaya akan sumber daya alam sehingga sangat potensial untuk dilakukan pengembangan mengenai produk biopolimer seperti bioplastik. Salah satu bahan dari alam yang dapat dimanfaatkan sebagai bahan pembuatan bioplastik adalah pati aren dan glukomanan dari umbi porang

Polisakarida yang dapat dimanfaatkan sebagai bahan baku bioplastik adalah pati aren. Pati aren menurut Haryadi (2002) memiliki kadar amilosa 29\%, sedangkan Rahim (2007) kadar amilosa 39\%, ikatan amilosa yang ada saling berdekatan dalam proses gelatinasi yaitu dengan pemanasan pada suhu $55-80^{\circ} \mathrm{C}$. Proses gelatinasi adalah perubahan yang terjadi pada granula pati pada waktu mengalami pembengkakan yang luar biasa dan tidak dapat kembali ke semula (Purnavita dan Utami, 2018)
Polisakarida lain yang dapat dimanfaatkan sebagai bahan pembuatan bioplastik adalah glukomanan karena mampu membentuk struktur serat-serat halus, (Purnavita dan Anggraeni, 2019). Glukomanan merupakan polisakarida yang tersusun oleh D-manosa dan D-glukosa dengan perbandingan 1,6:1 (Afriyani et al., 2013). Menurut Indrawati, et al. (2019) Glukomanan memiliki gugus asetil yang mampu berikatan dengan amilopektin pati membentuk ikatan silang sehingga diharapkan mampu menjadi bioplastik dengan ikatan yang semakin kuat dan memiliki sifat melindungi produk dari kerusakan

Bioplastik yang terbuat dari komposit glukomanan dan pati aren diharapkan memiliki nilai ekonomis dari segi harga karena pati aren memiliki harga yang lebih murah dibandingkan glukomanan dan keberlanjutan ketersediaan bahan baku bisa terjamin karena tidak hanya mengandalkan satu jenis bahan baku karena pati aren ketersediaannya hanya musiman. Sedangkan glukomanan akan memberikan sifat bioplastik yang lebih kuat.

Bioplastik yang hanya terdiri dari komposit glukomanan pati aren memiliki sifat yang masih mudah sobek dan rusak. Untuk menghasilkan bioplastik yang baik dari segi tensile elongation diperlukan penambahan plasticizer seperti gliserol. Gliserol merupakan salah satu plasticizer yang banyak digunakan karena cukup efektif mengurangi ikatan hidrogen internal sehingga akan meningkatkan jarak intermolekuler (Pradnya dan Arnata, 2015). Gliserol merupakan plastizicer yang bersifat hidrofilik, sehingga cocok untuk bahan pembentuk plastik yang bersifat hidrofobik seperti pati (Murni, S et al., 2013). Diperlukan penentuan kondisi optimum rasio glukomanan dengan pati aren dan jumlah gliserol yang terbaik untuk menghasilkan bioplastik dengan karakteristik yang baik dari segi ketahanan air, tensile strength, dan tensile elongation.

\section{METODOLOGI}

Bahan yang digunakan dalam penelitian ini adalah glukomanan, pati aren, PVA, aquades, dan gliserol. Variable bebas yang digunakan adalah rasio glukomanan terhadap pati aren yaitu $1: 0,5$; $1: 1 ; 1: 1,5 ;$ dan $1: 2$. Variabel bebas lainnya adalah penambahan gliserol yaitu sebanyak $0 \mathrm{ml}$ dan 10 
ml. Variabel tetap yang digunakan adalah jumlah penambahan PVA sebanyak 6 gram, aquades sebanyak $200 \mathrm{ml}$, suhu pemanasan $80^{\circ} \mathrm{C}$ dan waktu pemanasan 20 menit serta pengovenan pada suhu $60^{\circ} \mathrm{C}$ selama 24 jam. Sedangkan untuk variable terikatnya berupa sifat bioplastik yang dihasilkan yang terdiri dari ketahanan air, elongation, dan tensile strength

Pembuatan bioplastik dilakukan dengan melarutkan glukomanan ke dalam aquades, melarutkan pati aren ke dalam aquades, selanjutnya kedua larutan tersebut dicampur di dalam beaker glass dan diberi penambahan gliserol dan larutan poli vinil alkohol serta dipanaskan pada suhu $80^{\circ} \mathrm{C}$ selama 20 menit Setelah semua larutan tercampur homogen lalu dilanjutkan dengan pencetakan dan pengeringan dengan oven suhu $60^{\circ} \mathrm{C}$ selama 24 jam. Kemudian bioplastik dilepaskan dari cetakan dan dilanjutkan pengujian ketahanan air, uji tensile strength dan tensile elongation.(modifikasi penelitian Purnavita \& Utami 2018)

\section{HASIL DAN PEMBAHASAN}

Pada Gambar 1 terlihat bahwa tanpa penambahan gliserol (gliserol $=0 \mathrm{ml}$ ) menunjukkan hasil dengan adanya penambahan glukomanan terhadap pati aren mampu meningkatkan ketahanan bioplastik terhadap air dengan hasil paling tinggi pada rasio glukomanan : pati aren yaitu 1:1. Setelah itu pada penambahan rasio 1,5 dan 2 ketahanan air menurun. Hal ini dikarenakan pada rasio glukomanan : pati aren 1: 1 ikatan amilopektin pati dan glukomanan terjadi kuat dan menghasilkan ketahanan air yang cukup bagus. Pada penambahan rasio 1,5 dan 2 terjadi penurunan, karena semakin banyak kandungan amilopektin dalam pati yang tidak berikatan sehingga memudahkan untuk dapat larut air. Hal ini selaras dengan penelitian Indrawati, et al (2019) tentang ikatan amilopektin maizena dengan glukomanan.

Adanya penambahan gliserol untuk rasio glukomanan dan pati aren berdampak menurunkan ketahanan terhadap air dibandingkan dengan tanpa penambahan gliserol, karena adanya plasticizer gliserol meregangkan ikatan antar molekul amilosa sehingga ada kemungkinan celah dan air dapat masuk. Hasil penelitian ini selaras dengan penelitian Anandito, et al. (2012) yang menyatakan bahwa adanya penambahan gliserol secara nyata mampu meningkatkan kelarutan film. Hal ini dikarenakan gliserol bersifat hidrofilik yaitu mudah larut dalam air sehingga dapat menurunkan ketahanan bioplastik terhadap air (Sitompul dan Zubaidah, 2015).

Menurut Fathanah et al. (2017), semakin besar daya serap airnya maka plastik kurang mampu melindungi produk dari air yang dapat menyebabkan produk cepat rusak atau berkurang kualitasnya. Bioplastik yang memiliki tingkat ketahanan air yang tinggi terdapat pada rasio glukomanan : pati aren (1:1) tanpa penambahan gliserol, Hal ini menunjukkan bahwa dengan adanya glukomanan memungkinkan terjadinya ikatan silang dengan amilopektin, sehingga ketahanan air lebih tinggi. Sedangkan hasil ketahanan air bioplastik terendah pada rasio glukomanan : pati aren 1:1 dengan penambahan gliserol $10 \mathrm{ml}$, hal ini dikarenakan kemungkinan semua glukomanan telah berikatan dengan amilopektin, sehingga $-\mathrm{OH}$ gliserol meregangkan ikatan antar molekul (ikatan hidrogen) amilosa, dan menyebabkan air dapat masuk sehingga ketahanannya berkurang.

Pada Gambar 2 terlihat bahwa adanya penambahan gliserol cenderung meningkatkan elongation (kemuluran) bioplastik pada semua rasio glukomanan : pati aren dibandingkan dengan tanpa penambahan gliserol. Hal ini sesuai dengan sifat gliserol sebagai plasticizer yaitu meningkatkan fleksibilitas bioplastik. Penambahan gliserol akan meningkatkan

mobilitas molekuler rantai polimer karena adanya ikatan percabangan sehingga bioplastik semakin elastis dan perpanjangan saat putus cenderung akan meningkat, hal ini serupa dengan penelitian yang telah dilakukan oleh Nuriyah, et al (2018) mengenai pengaruh jenis plasticizer terhadap bioplastik dari pati ubi jalar cilembu

Pada gambar 2, juga terlihat bahwa semakin tinggi rasio glukomanan : pati aren yang ditambahkan, maka semakin kecil nilai elongation bioplastik yang dihasilkan. Hal ini disebabkan oleh sifat amilosa pati aren membuat struktur bioplastik menjadi keras dan kaku sehingga fleksibilitasnya menurun. Menurut Rahim, et al (2011) elongasi menurun karena ikatan yang terjadi antara molekul pati semakin rapat dan kompak sehingga akan 
menyebabkan film menjadi kuat. Dengan semakin kuatnya film yang terbentuk maka semakin sulit untuk memanjang sehingga memperkecil perpanjangan film.

Dari grafik pada gambar 2 nilai elongation tertinggi pada rasio glukomanan : pati aren $1: 1$ dengan penambahan $10 \mathrm{ml}$ gliserol. Nilai elongation ini terjadi karena adanya ikatan percabangan antara amilopektin pati dengan glukomanan, dan ikatan gugus $\mathrm{OH}$ gliserol dengan amilosa pati sehingga membuat bioplastik lebih fleksibel.

\section{Analisis Tensile strength Bioplastik}

Gambar 3 menunjukkan dengan penambahan gliserol $10 \mathrm{ml}$ menurunkan nilai kuat tarik dari bioplastik, sebab adanya $-\mathrm{OH}$ gliserol memutus rantai yang panjang dan membuat rantai karbon bioplastik yang terbentuk menjadi lebih pendek dan bercabang. Penelitian ini selaras dengan penelitian Sinaga, et al (2014) yang menyatakan adanya gliserol memperbanyak jumlah ikatan percabangan pada bioplastik sehingga. menurunkan kekuatan intermolekuler rantai polimer bioplastik dari umbi talas

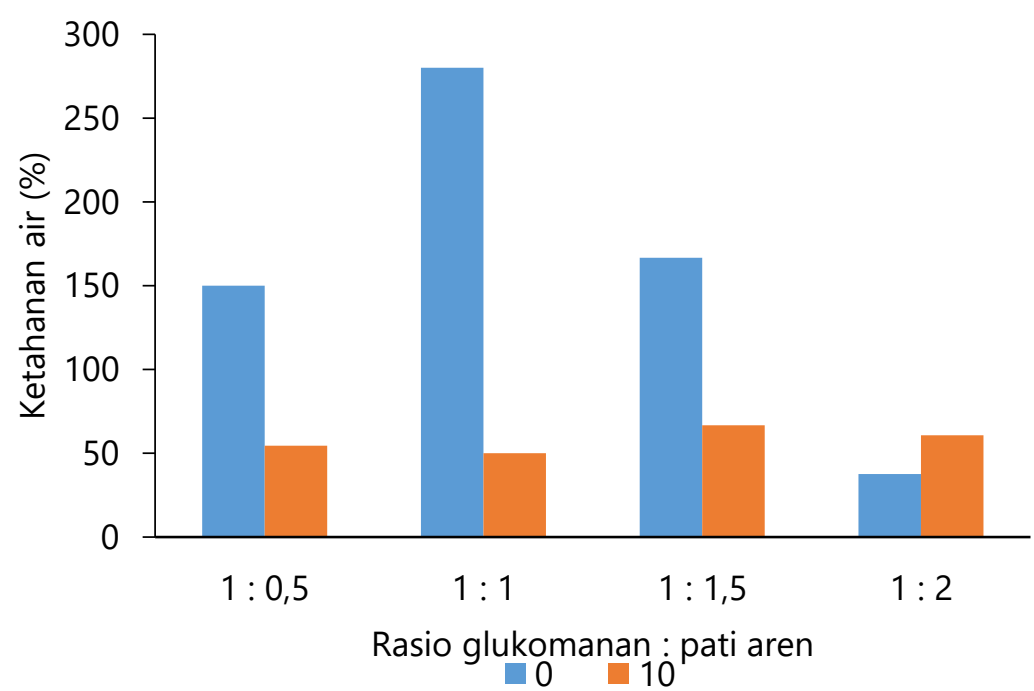

Gambar 1. Pengaruh rasio glukomanan : pati aren dan gliserol terhadap ketahanan air bioplastik

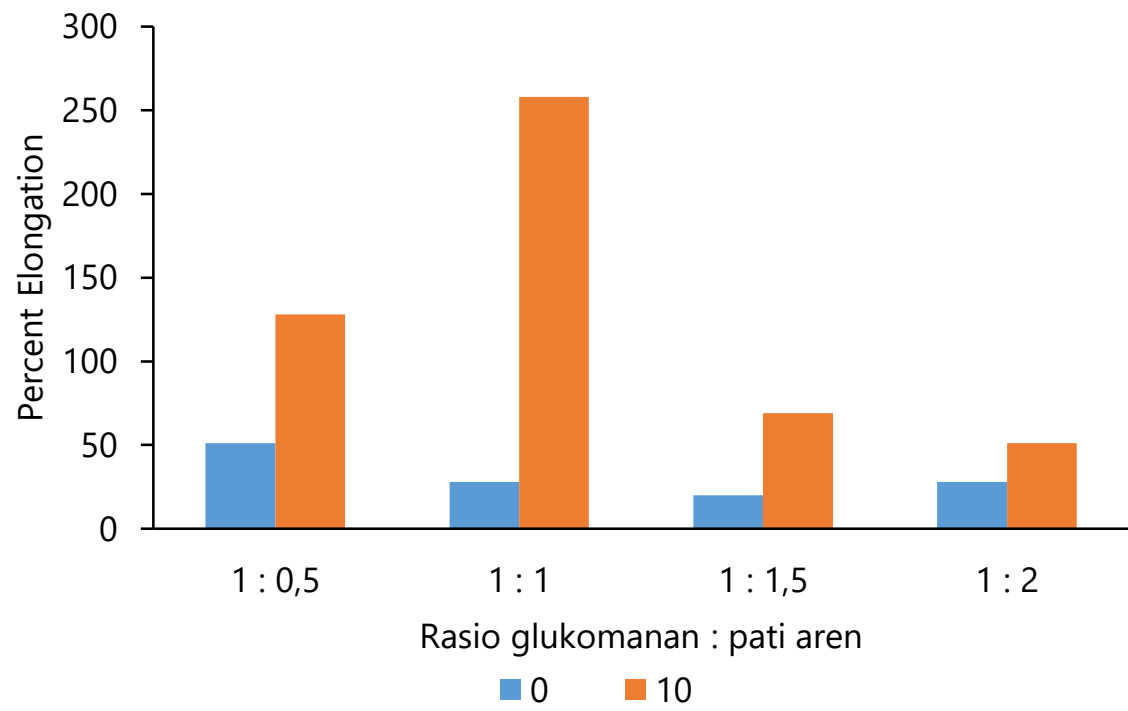

Gambar 2. Pengaruh rasio glukomanan : pati aren dan gliserol terhadap elongation bioplastik 
Tanpa penambahan gliserol (gliserol $=0 \mathrm{ml}$ ) adanya penambahan rasio glukomanan : pati aren meningkatkan hasil kuat tarik bioplastik. Hal ini dapat dijelaskan karena pati aren memiliki kandungan amilosa yang mampu berikatan ketika dipanaskan, dengan semakin banyaknya pati aren yang ditambahkan, maka semakin banyak ikatan amilosa yang terbentuk

selaras dengan penelitian yang dilakukan Rahim, et al. (2011) semakin banyak kandungan amilosa sebagai penyusun edible film menyebabkan film semakin kuat, sehingga akan semakin tinggi gaya yang diperlukan per satuan luas permukaan film. Selain itu ikatan silang yang terjadi antara amilopektin pati dengan glukomanan turut memperkuat bioplastik yang dihasilkan

Selanjutnya, pada penambahan gliserol 10 $\mathrm{ml}$, dengan adanya penambahan rasio glukomanan : pati aren semakin banyak, hasil menunjukkan nilai kuat tarik bioplastik kecil, hal ini dikarenakan semakin banyak kandungan amilosa yang ada, sehingga semakin banyak pula ikatan amilosa yang diputus oleh $-\mathrm{OH}$ gliserol, menjadi ikatan bercabang dan pendek yang menyebabkan penurunan nilai kuat tarik bioplastik karena berkurangnya kekuatan antar molekul panjang amilosa.

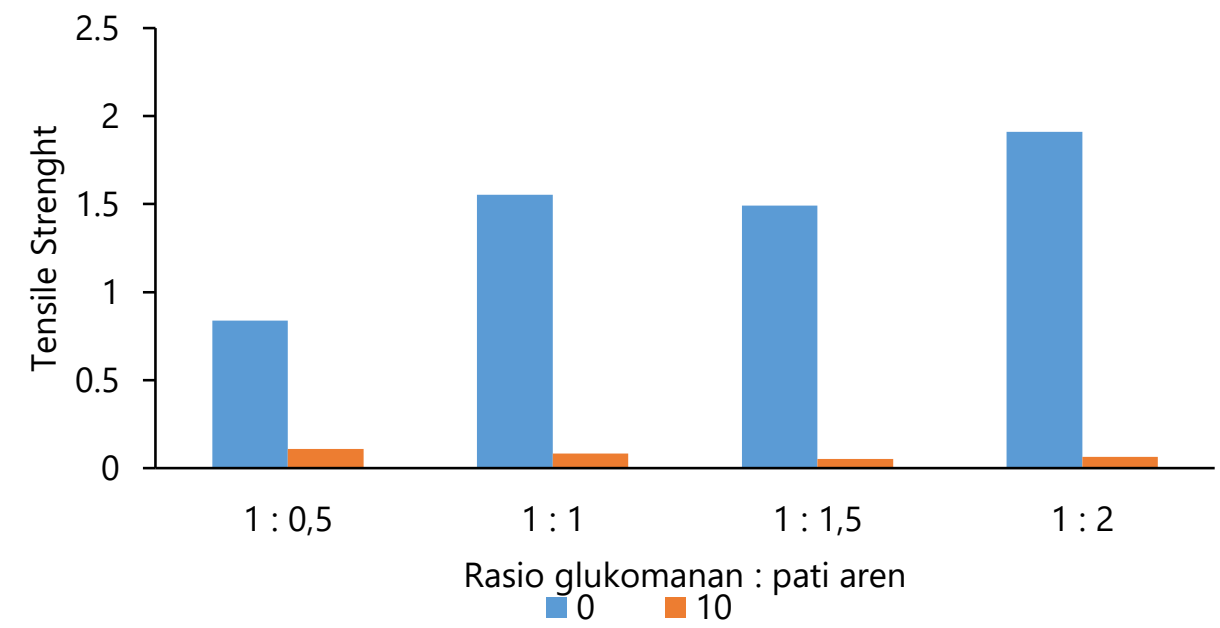

Gambar 3. Pengaruh rasio glukomanan : pati aren dan gliserol terhadap tensile strength bioplastik

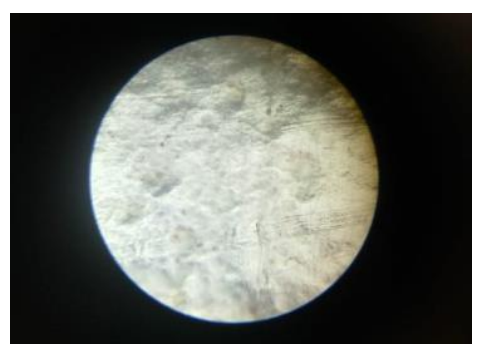

a

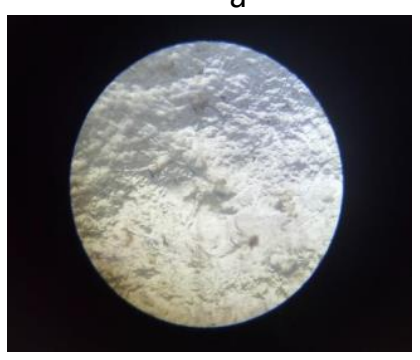

C

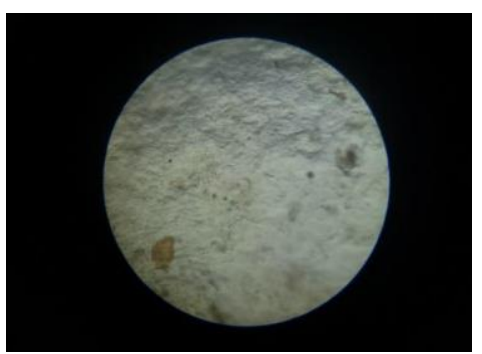

b

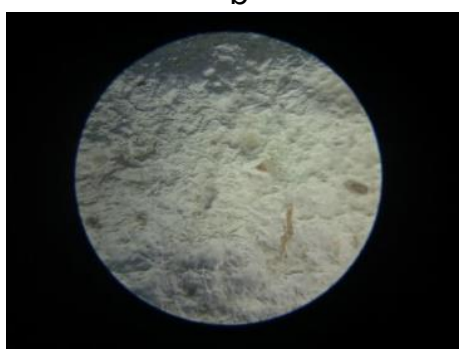

d

Gambar 4. Pengaruh rasio glukomanan : pati aren tanpa gliserol terhadap morfologi bioplastik (a) $1: 0,5 ;(b)$ $1: 1 ;$ (c) $1 ; 1,5 ;$ (d) $1: 2$. 


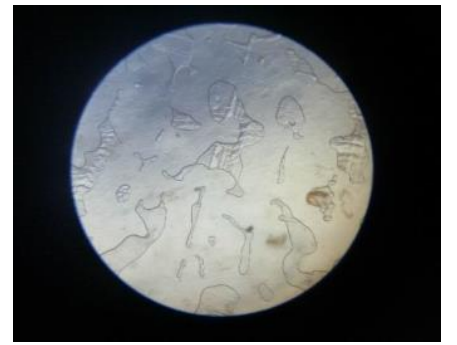

a

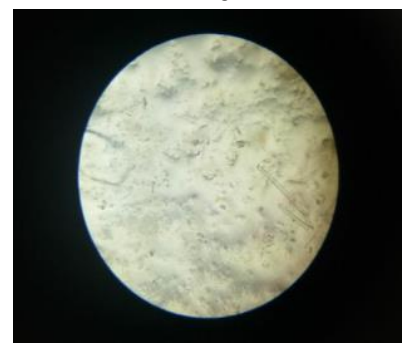

C

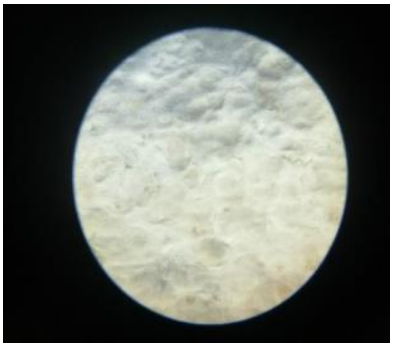

b

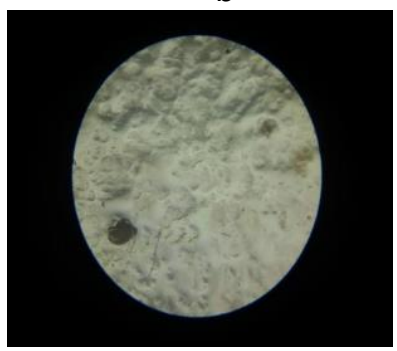

d

Gambar 5. Pengaruh rasio glukomanan : pati aren dengan gliserol terhadap morfologi bioplastik (a) $1: 0,5$; (b) $1: 1 ;$ (c) $1 ; 1,5 ;$ (d) $1: 2$.

\section{Analisa Morfologi Plastik}

Pada gambar 4 morfologi bioplastik tanpa penambahan gliserol memperlihatkan permukaan bioplastik kurang halus, dengan semakin banyak rasio glukomanan : pati aren yang ditambahkan maka akan semakin halus permukaan. Hal ini sesuai dengan karakteristik glukomanan yang mampu berikatan dengan amilopektin pati. Pada penambahan rasio glukomanan : pati aren $1: 1$ memiliki permukaan yang lebih halus dibandingkan dengan rasio yang lain, dikarenakan adanya ikatan glukomanan dan pati aren yang bagus.

Pada gambar 5 morfologi bioplastik dengan penambahan gliserol memperlihatkan permukaan bioplastik yang lebih halus dibandingkan tanpa penambahan gliserol pada penambahan semua rasio glukomanan : pati aren. Hal ini sesuai dengan karakteristik gliserol sebagai plasticizer yaitu membuat bioplastik menjadi lebih fleksibel dengan cara meregangkan ikatan antar molekul penyusun bioplastik. (Kamsiati, et al., 2017). Pada penambahan rasio glukomanan : pati aren $1: 0,5$ memiliki permukaan yang memiliki bercak air, hal ini dikarenakan pada rasio ini dirasa penambahan gliserol $10 \mathrm{ml}$ terlalu banyak sehingga tidak berikatan dan menghasilkan bioplastik yang sedikit basah.

\section{KESIMPULAN}

Hasil penelitian menunjukkan bahwa berbagai rasio glukomanan dan pati aren dengan penambahan gliserol berpengaruh terhadap karakteristik bioplastik. Pada penambahan gliserol $0 \mathrm{ml}$ (tanpa gliserol), komposit bioplastik dengan perbandingan glukomana:pati aren sebesar 1:1 menghasilkan nilai ketahanan terhadap air yang tertinggi.morfologi plastik cukup bagus dan nilai tensile strength yang cukup tinggi, tetapi nilai tensile elongation rendah. Sedangkan pada percobaan dengan penambahan gliserol $10 \mathrm{ml}$, komposit bioplastik dengan perbandingan glukomanan:pati aren sebesar 1:1 menghasilkan nilai tensile elongation yang tertinggi dan hasil morfologi bagus, tetapi nilai tensile strength dan ketahanan airnya rendah. Komposisi komposit bioplastik yang direkomendasikan adalah rasio glukomanan:pati aren sebesar 1:1 dengan penambahan gliserol kurang dari $10 \mathrm{ml}$.

\section{DAFTAR PUSTAKA}

Afriyani, Y.D., Nirmala, A. and Aryanti, N., 2013. Pemisahan konjak glukomanan menggunakan membran ultrafiltrasi. Jurnal Teknologi Kimia dan Industri, 2(4), pp.164-169. 
Anandito, R.B.K. and Bukhori, A., 2012. Pengaruh Gliserol Terhadap Karakteristik Edible Film Berbahan Dasar Tepung Jali (Coix Lacryma-Jobi L.). Jurnal Teknologi Hasil Pertanian, 5(1):17-23

Fathanah, U., Lubis, M., \& Siddiqil, M. 2017. Pengaruh Penambahan Kitosan Dan Gliserol Terhadap Sifat Mekanik, Morfologi, Dan Waktu Degradasi Bioplastik Berbasis Pati Kulit Ubi Kayu (Manihot Utilissima), Proceeding Seminar Nasional Politeknik Negeri Lhokseumawe

Haryadi, 2002. The Current Status and Future Prospects of Sago Palms in Java, In: Kainuma, K., Okazaki, M., Toyoda, Y. and Cecil, J. E., (eds.) 2002. New Frontiers in Sago Palm Studies.

Indrawati, C., Harsojuwono, B. \& Hartiati, A. 2019. Karakteristik Komposit Bioplastik Glukomanan Dan Maizena Dalam Pengaruh Variasi Suhu Dan Waktu Gelatinisasi, Jurnal Rekayasa dan Manajemen Agroindustri, 7(3):468-477

Kamsiati, E, Herawati, H. and Purwani, E.Y., 2017. Potensi Pengembangan Plastik Biodegradable Berbasis Pati Sagu Dan Ubikayu di Indonesia, Jurnal Penelitian dan Pengembangan Pertanian, 36(2):67-76. DOI: 10.21082/jp3.v36n2.2017.p6776

Murni, S.W, Pawignyo H, Widyawati, D. \& Sari, N. 2013. Pembuatan Edible Film dari Tepung Jagung (Zea Mays L.) dan Kitosan, Prosiding Seminar Nasional Teknik Kimia "Kejuangan" Pengembangan Teknologi Kimia untuk Pengolahan Sumber Daya Alam Indonesia, Yogyakarta 5 Maret 2013

Nuriyah, L., Saroja, G., Ghufron, M., Razanata, A. \& Rosid, N.F., 2018. Karakteristik Kuat Tarik dan Elongasi Bioplastik Berbahan Pati Ubi Jalar
Cilembu dengan Variasi Jenis Pemlastis, Natural $B, 4(4): 177-182$

Pradnya, I.G.A.A.M. and Arnata, I.W., 2015. Pengaruh Campuran Bahan Komposit Dan Konsentrasi Gliserol Terhadap Karakteristik Bioplastik Dari Pati Kulit Singkong Dan Kitosan, Jurnal Rekayasa Dan Manajemen Agroindustri, 3(3):41-50

Purnavita, S. \& Anggraeni, A. 2019. Pengaruh Penambahan Beeswax Dan Gliserol Terhadap Karakteristik Poliblend Glukomanan - Polivinil Alkohol (PVA), Inovasi Teknik Kimia. 4(2):33-39

Purnavita, S. \& Utami, W. 2018. Pembuatan Plastik Biodegradable Dari Pati Aren Dengan Penambahan Aloe Vera, Inovasi Teknik Kimia, 3(2):31-3

Rahim, A. 2007. Pengaruh Cara Pengolahan Instant Starch Noodle dari Pati Aren terhadap Sifat Fisikokomia dan Sensoris, Journal Agroland, 14(3):269- 274.

Rahim, A., Alam, N., Haryadi, H. \& Santoso, U. 2011. Karakteristik edibel film dari pati aren amilosa tinggi dan aplikasinya sebagai pengemas bubuk bumbu mie. Jurnal Agroland, 18(1):15-21,

Sinaga, R.F, Ginting, G.M., Ginting, M.H.S. \& Hasibuan, R., 2014, Pengaruh Penambahan Gliserol Terhadap Sifat Kekuatan Tarik Dan Pemanjangan Saat Putus Bioplastik Dari Pati Umbi Talas, Jurnal Teknik Kimia USU, 3(2):19-24. DOI: 10.32734/jtk.v3i2.1608

Sitompul, A, \& Zubaidah, E. 2017, Pengaruh Jenis Dan Konsentrasi Plasticizer Terhadap Sifat Fisik Edible Film Kolang Kaling (Arenga Pinnata), Jurnal Pangan dan Agroindustri, 5(1):13-25 